“C 2018 IEEE. Personal use of this material is permitted. Permission from IEEE must be obtained for all other uses, in any current or future media, including reprinting/republishing this material for advertising or promotional purposes, creating new collective works, for resale or redistribution to servers or lists, or reuse of any copyrighted component of this work in other works." 


\section{Optimization of a Five-Phase E-core Bearingless Flux-Switching Permanent Magnet Motor for Flywheel Batteries}

\author{
Zhijia Jin, Xiaodong Sun, Long Chen, Zebin Yang \\ Automotive Engineering Research Institute \\ Jiangsu University \\ Zhenjiang, China (212013) \\ jzjxcc@163.com,xdsun@ujs.edu.cn, chenlong@ujs.edu.cn, \\ zbyang@ujs.edu.cn
}

\begin{abstract}
In this paper, a five-phase E-core bearingless fluxswitching permanent magnet (BSFPM) motor for flywheel batteries is proposed and optimized. First, the structure and the principle of the BSFPM motor are described simply. Second, the trial and error method is used to obtain the most reasonable relationship of center tooth arc width and edge tooth arc width, and then the electromagnetic torque and suspension force after optimization are got. The motor after optimization has smoother five-phase flux-linkage and the disturbance of the torque and suspension force decrease.
\end{abstract}

Keywords-five-phase; BSFPM motor; flywheel battery; structure optimization; suspension force;

\section{INTRODUCTION}

The flywheel battery is a kind of short-time energy storage system with many advantages, such as high power capability, high reliability and long service time, which mostly depend on the bearingless motor. And bearingless permanent magnet (BPM) motor has been widely researched due to its advantages of non-contact, no friction, no lubrication, small size and high power density in the past two decades [1-2]. However, the conventional bearingless permanent magnet motor used in the flywheel battery has the shortcomings of relatively poor heat dispersion and high speed limitation due to the inherent characteristic that the permanent magnets are located on or in the rotor. Meanwhile, research on the multi-phase motor has been a hot spot in recent years because of higher torque density, less copper loss and fault-tolerant control compared to the ordinary three-phase motor. Therefore, a five-phase E-core bearingless flux-switching permanent magnet (BSFPM) motor with higher power density and lower copper loss has been proposed [3-6].

Currently, the predominant performances make BSFPM motor a center issue such as strong robustness, easy thermal dissipation and relatively simple structure. Hence, this paper will focus on the optimization of the proposed five-phase Ecore BSFPM motor [7-8]. The characteristics of the BSFPM motor have been introduced firstly in this paper. Then, the principle of BSFPM motor is discussed. Moreover, the static characteristics of a 10/18 five-phase E-core BSFPM motor

\author{
JianGuo Zhu, YouGuang Guo, Gang Lei \\ School of Electrical, Mechanical and Mechatronic Systems \\ University of Technology, Sydney \\ Sydney, Australia (2007) \\ jianguo.zhu@uts.edu.au, Youguang.Guo-1@uts.edu.au, \\ Gang.Lei@uts.edu.au
}

are investigated through optimizing the structure of the Ecore stator. Finally, the torque and suspension force are compared with those of the initial state.

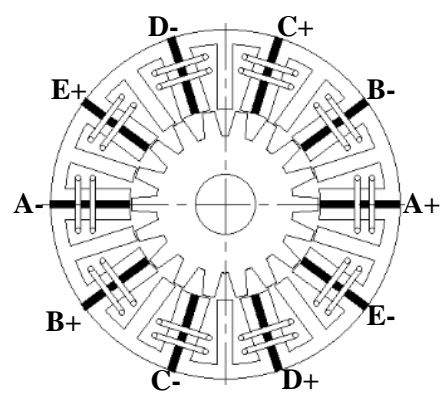

Fig. 1 The structure of BSFPM motor

\section{THE STRUCTURE AND PRINCIPLE OF BPMFSM}

\section{A. The Structure of BSFPM motor}

The structure of the proposed motor is shown in Fig. 1. As shown, the PMs are located between ten E-shaped laminations, which make up the E-core stator. Torque and suspension windings are wound on the PMs and two stator teeth adjacent to PMs. Additionally, a gear-shaped rotor is located in the central position.

\section{B. The Principe of BSFPM motor}

Fig. 2 (a)-(c) show the operation principle. In Fig. 2 (a), the rotor tooth $\mathrm{P}_{2}$ aligns with the right stator tooth adjacent to the PM, in which case, the flux linkage is assumed in a counterclockwise direction. As the motor moves to Fig. 2 (b), it is considered as a balance position. In Fig. 2(c), the rotor tooth $\mathrm{P}_{1}$ aligns with the left stator teeth. Thus, the flux linkage is similar to that in Fig. 2(a) while in an opposite direction. Hence, the back-EMF is generated.

As for suspension force, it is generated by applying current to the suspension windings. Taking $\mathrm{x}$-direction as example, after the A+ phase and A- phase suspension windings work, the flux linkages are not equal in their own gap. According to the Maxwell Principe, the force in $\mathrm{x}$ direction is produced. Similarly, suspension force in $y$ direction can be generated by controlling the suspension current in other phases. 


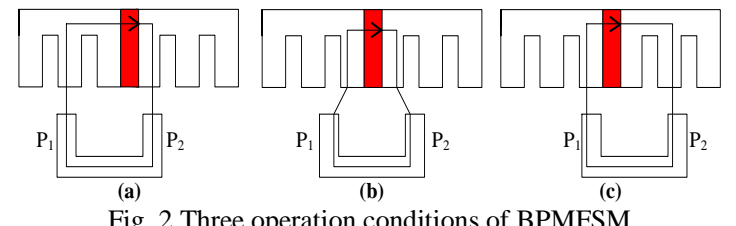

Fig. 2 Three operation conditions of BPMFSM

\section{MOtOR STRUCTURE OPTIMIZATION AND SiMULATION}

As we all know, a relatively wide tooth can increase flux but can also cause serious magnetic flux leakage. Therefore, an optimization method has been presented based on trial and error method [9]. Moreover, the original parameters of the proposed five-phase BSFPM motor have been given in Table I.

Currently, most E-core stators have the same tooth arc width. However, the center tooth and the edge tooth may be not equal due to the difference in flux. The optimization range of the center tooth arc width $H_{s 1}$ and the edge tooth arc width $H_{s 2}$ can be determined and divided into $m$ values and $n$ values, respectively, according to the structure. $m \times n$ models are built and their torque and suspension force can be compared with the initial value. Therefore, the suitable relationship between the center tooth arc width $H_{s 1}$ and the edge tooth arc width $H_{s 2}$ is got.

Table I Parameters of the proposed E-core BSFPM motor

\begin{tabular}{ccc}
\hline \hline Symbol & Quabtity & Value \\
\hline$H_{s 1}$ & Stator center tooth arc width & $2.33 \mathrm{~mm}$ \\
$H_{s 2}$ & Stator edge tooth arc width & $2.33 \mathrm{~mm}$ \\
$H_{s l o t}$ & Stator slot width & $6.5 \mathrm{~mm}$ \\
$D_{i}$ & Rotor inner diameter & $16 \mathrm{~mm}$ \\
$D_{o}$ & Rotor outer diameter & $24.5 \mathrm{~mm}$ \\
$H_{r}$ & Rotor tooth arc width & $3.4 \mathrm{~mm}$ \\
$g$ & Air gap length & $0.5 \mathrm{~mm}$ \\
$L_{p m}$ & Permanent magnet length & $21 \mathrm{~mm}$ \\
$H_{p m}$ & Permanent magnet thickness & $2 \mathrm{~mm}$ \\
$N$ & Number of winding turns & 60 \\
\hline \hline
\end{tabular}

According to the given parameters, simulation models have been built. Then, the electromagnetic torque and suspension force are analyzed in different values of stator center arc width $H_{s l}$ and stator edge arc width $H_{s 2}$. Then, the results are shown in Figs. 3-4. Fig. 3 shows the electromagnetic torque before and after optimization. And in Fig. 4, the waveform of the five-phase current is given. As shown, when the center tooth arc width and the edge tooth arc width are $3 \mathrm{~mm}$ and $3.6 \mathrm{~mm}$ respectively, the torque has smaller fluctuations.

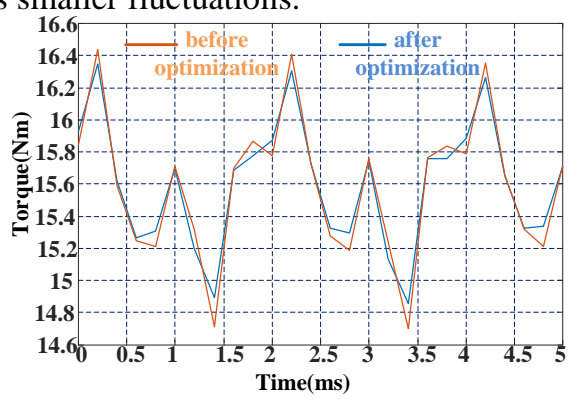

Fig. 3 Torque after and before optimization

\section{CONCLUSION}

In this paper, a proposed 10/18 five-phase E-core BSFPM motor has been optimized and analyzed. Meanwhile, its operation principle is introduced. Based on the original model, a number of similar structures have been simulated to reflect the most reasonable relationship of center tooth and edge tooth of the E-core stator. The results show that when the ratio of edge tooth arc width $H_{s 2}$ to center tooth arc width $H_{s 1}$ is 1.2 , the proposed five-phase BSFPM motor has better performance.

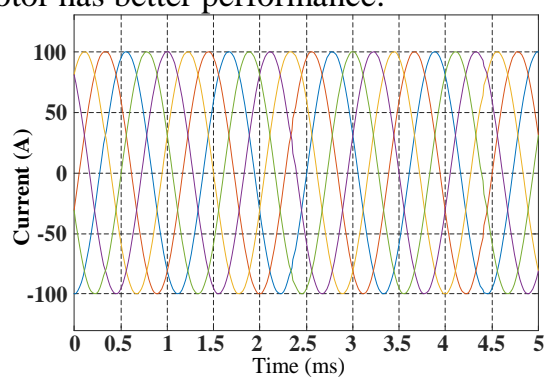

Fig. 4 Waveform of the five-phase current

\section{ACKNOWLEDGEMENT}

This work was supported by the National Natural Science Foundation of China under Projects 51305170, 51475214, and 51475213, the Natural Science Foundation of Jiangsu Province of China under Projects BK20170071, the Key Project of Natural Science Foundation of Jiangsu Higher Education Institutions under Project 17KJA460005, the Six Categories Talent Peak of Jiangsu Province under Projects 2015-XNYQC-003 and 2014-ZBZZ-017, the "333 project" of Jiangsu Province under Project BRA2017441, and the Priority Academic Program Development of Jiangsu Higher Education Institutions (PAPD).

\section{REFERENCES}

[1] X. Sun, L. Chen and Z. Yang, "Overview of bearingless permanentmagnet synchronous motors," IEEE Transactions on Industrial Electronics, vol. 60, no. 12, pp. 5528-5538, Dec. 2013.

[2] T. Nussbaumer, P. Karutz, F. Zurcher and J. W. Kolar, "Magnetically levitated slice motors-An overview," IEEE Transactions on Industry Applications, vol. 47, no. 2, pp. 754-766, Mar./Apr. 2011.

[3] G. Lei, J. Zhu, Y. Guo, C. Liu and B. Ma, "A review of design optimization methods for electrical machines", Energies, vol. 10, no. 12, Art. no. 1962, pp. 1-31, Nov. 2017.

[4] X. Sun, Z. Shi, L. Chen, and Z. Yang, "Internal model control for a bearingless permanent magnet synchronous motor based on inverse system method," IEEE Transactions on Energy Conversion, vol. 31. pp. 1539-1548, Nov. 2016.

[5] X. Sun, L. Chen, H. Jiang, Z. Yang, J. Chen and W. Zhang, "Highperformance control for a bearingless permanent magnet synchronous motor using neural network inverse scheme plus internal model controllers," IEEE Transactions on Industrial Electronics, 2016, 63(6): 3479-3488, Feb. 2016.

[6] W. Gruber, W. Briewasser, M. Rothbock and R. T. Schöb, "Bearingless slice motor concepts without permanent magnets in the rotor,” Proc. Industrial Technology (ICIT), 2013 IEEE International Conference on, pp. 259, 265, 25-28 Feb. 2013.

[7] T. Raminosoa, C. Gerada, and M. Galea, "Design considerations for a fault-tolerant flux-switching permanent-magnet machine," IEEE Transactions on Industrial Electronics, vol. 58, no. 7, pp. 2818-2825, July. 2011.

[8] X. Sun, L Chen, Z Yang, and H. Zhu, "Speed-sensorless vector control of a bearingless induction motor with artificial neural network inverse speed observer," IEEE/ASME Transactions on Mechatronics, 2013, 18(4): 1357-1366, June. 2012.

[9] G Lei, J Zhu, and Y Guo, "Multidisciplinary design optimisation methods for electrical machines and drive systems," Springer-Verlag, Berlin Heidelberg, 2016, pp. 25-69. 